\section{The ICER Working Paper Series on Entrepreneurship and Innovation}

ISSN 2048-2426

WP8

New Firm Formation and Sustainable

Regional Economic Development Relevance, Empirical Evidence, Policies

by

Michael Fritsch

Number of Pages: 11

INTERNATIONAL CENTRE FOR ENTREPRENEURSHIP RESEARCH

Essex Business School

University of Essex Elmer Approach

Southend-on-Sea, Essex

SS1 1LW, UK

Tax: +441702 328387

www.essex.ac.uk/ebs/research/cer

General correspondence to imitra@essex.ac.uk
University of Essex

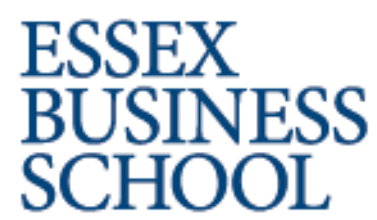

External Advisors:

Prof David Smallbone

Prof Mathew Manimala

Prof Gunnar Prause 


\title{
New Firm Formation and Sustainable Regional Economic Development - Relevance, Empirical Evidence, Policies ${ }^{1}$
}

\author{
Michael Fritsch
}

Corresponding Author(s):

Michael Fritsch

Professor of Economics

Chair of Business Dynamics, Innovation, and Economic Change

Friedrich Schiller University Jena

Carl-Zeiss-Str. 3

D-07743 Germany

E-mail:m.fritsch@uni-jena.de

1 This discussion paper was prepared for the panel "Sustainable Regional Economic Development: Developing policies for Social Sustainability and Economic Security through New Firm Formation" at the 12th IEF Conference, 4-6 September 2013, Vilnius, Lithuania 


\section{Table of Content}

Introduction 3

The basic relationships 3

The magnitude of the direct and the indirect effects 5

Differences of the effect of new business formation across regions 6

The persistence of regional entrepreneurship and the scope for policy 8

Questions for discussion $\quad 8$

$\begin{array}{ll}\text { References } & 9\end{array}$ 


\section{Introduction}

The belief that new business formation is a source of economic growth is widespread. This belief has been a strong motivation for a great deal of research in entrepreneurship. It has also motivated politicians in many countries to devise strategies aimed at stimulating the formation of new firms. However, the theoretical as well as the empirical foundation for this belief are remarkably weak. Empirical research on the issue started late and only recently have researchers begun to assess the effects of new businesses on economic development in detail.

The effect of new business formation on regional development is an important field of research. A proper understanding of these relationships may provide valuable inputs for policies aimed at stimulating growth. This short introduction provides an overview on the current state of knowledge about the effects that new businesses have on regional development. The focus is on regions for three reasons. First, geographical units of observation are much better suited for such an analysis than are industries. ${ }^{1}$ Second, empirical research has shown that the magnitude of the effects of new business formation on growth differs considerably across regions pointing to the importance of region-specific factors. Third, regions are an important arena for development policy (for an extensive review see Fritsch, 2013).

\section{The basic relationships}

The basic mechanism that transforms new business formation into growth is the competition between entries and incumbent firms. New business formation is a challenge to incumbents that results in intensified competition. The overall effect of new business formation on development results from this competitive process. It includes not only the development of the start-ups-the direct effect-but also development of the incumbent firms caused by entry of the newcomers-the indirect effect (Figure 1). These indirect effects are influenced by diverse factors that can be specific to the respective firms, markets, or regions.

\footnotetext{
${ }^{1}$ The reasoning behind this statement is that if industries follow a lifecycle (Klepper, 1997), then the number of entries and the start-up rate will be relatively high in the early stages of the lifecycle when the industry is growing, and comparatively low in later stages when the industry is in decline. In such a setting, the positive correlation between the start-up rate and the development of the industry in subsequent periods can hardly be regarded as evidence for a positive causal effect of entry on growth but it may be appropriate to view entry as a symptom of industry development. Accordingly, the results of empirical analyses at the regional level can be considerably different from those found in an analysis at the industry level).
} 


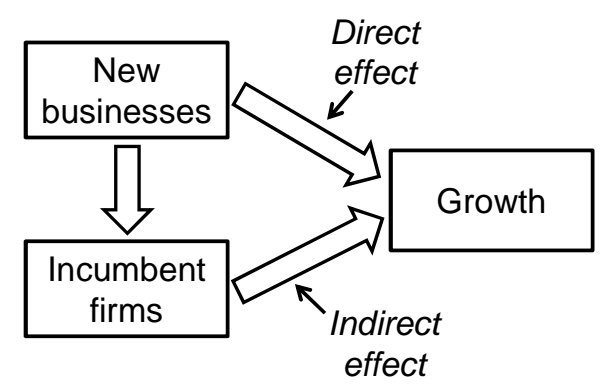

Figure 1: Direct and indirect effects of new businesses on growth

One important indirect effect of new business formation is the displacement of incumbents by new competitors. Given that competition and market selection are based on survival of the fittest, firms with relatively high productivity will remain in the market, whereas those with low productivity will either have to reduce their output or exit. This type of market selection leads to an overall productivity increase, so that fewer resources are needed to produce the given amount of goods and services. Hence, for regional output to remain constant, the increased productivity due to new business formation should cause a decline in employment instead of the creation of additional jobs. Thus, the effect of new business formation on the number of jobs will not necessarily be positive but could just as well be negative.

There are a number of further indirect effects of entries that may promote competitiveness of the regional economy and growth. Main such effects are:

- Securing efficiency and stimulating productivity by contesting established market positions.

- Acceleration of structural change. Frequently, structural change is mainly accomplished by a turnover of economic units, that is, by the entry of new firms and the simultaneous exit of established incumbents. In this case, the incumbents do not make the necessary internal changes, but are substituted for by newcomers. This type of process is emphasized in J. A. Schumpeter's (1911/1934, 1942) concept of creative destruction and by Alfred Marshall's (1920) analogy of a forest in which the old trees must fall to make way for new ones.

- Amplified innovation, particularly the creation of new markets. There are many examples of radical innovations introduced by new firms (Baumol, 2004).

- Greater variety of products and problem solutions. If the products of a newcomer differ from those of the incumbents, or if an entrant introduces significant process innovation, the result will be a greater variety of available goods and problem-solving methods. Such increased due to new supplies may intensify the division of labor, as well as follow-up innovation, and, therefore, may generate significant economic development (Boschma, 2004; Saviotti and Pyka, 2004). Greater variety can particularly mean a diversification of the regional industry structure and the respective knowledge base that may make regions more resilient to external shocks (Boschma and Frenken, 2011). 
Taken together, these effects can lead to an improved competitiveness of the regional economy-including the incumbent firms-and in this way generate growth. Recent research has shown that it may take a number of years until these positive effects of new business formation on regional growth become visible. This means that new business formation is not a quick solution to problems of lacking growth.

\section{The magnitude of the direct and the indirect effects}

Research has for a long time focused on the direct effects of new businesses-the development of the newly founded firms-and has largely neglected their indirect effects. Statements of politicians about the contribution of new business formation to growth almost always only regard the direct effects by providing number of jobs that have been created by start-ups, but are completely silent about how many jobs have been lost in incumbent firms due to the new competitors. We know, however, from empirical analyses of start-up cohorts that new businesses do create a considerable number of jobs, but that the share of employment in new businesses in overall employment is not overwhelming. Moreover, many of the new businesses fail and have to exit the market after only a rather short period of time. ${ }^{2}$ Most of the surviving new businesses stay very small, often without any employee. Some exceptional start-ups, the so-called gazelles, may show high growth, but the possibility of high growth is not at all limited to newcomers but can also be found for incumbent firms. The typical start-up cohort shows some employment increase in the first one or two years followed by continuing decline. The probable reason for this employment decline is that the job losses due to exits are not fully compensated by growth of surviving firms. Figure 2 shows this pattern for start-up cohorts in West Germany.

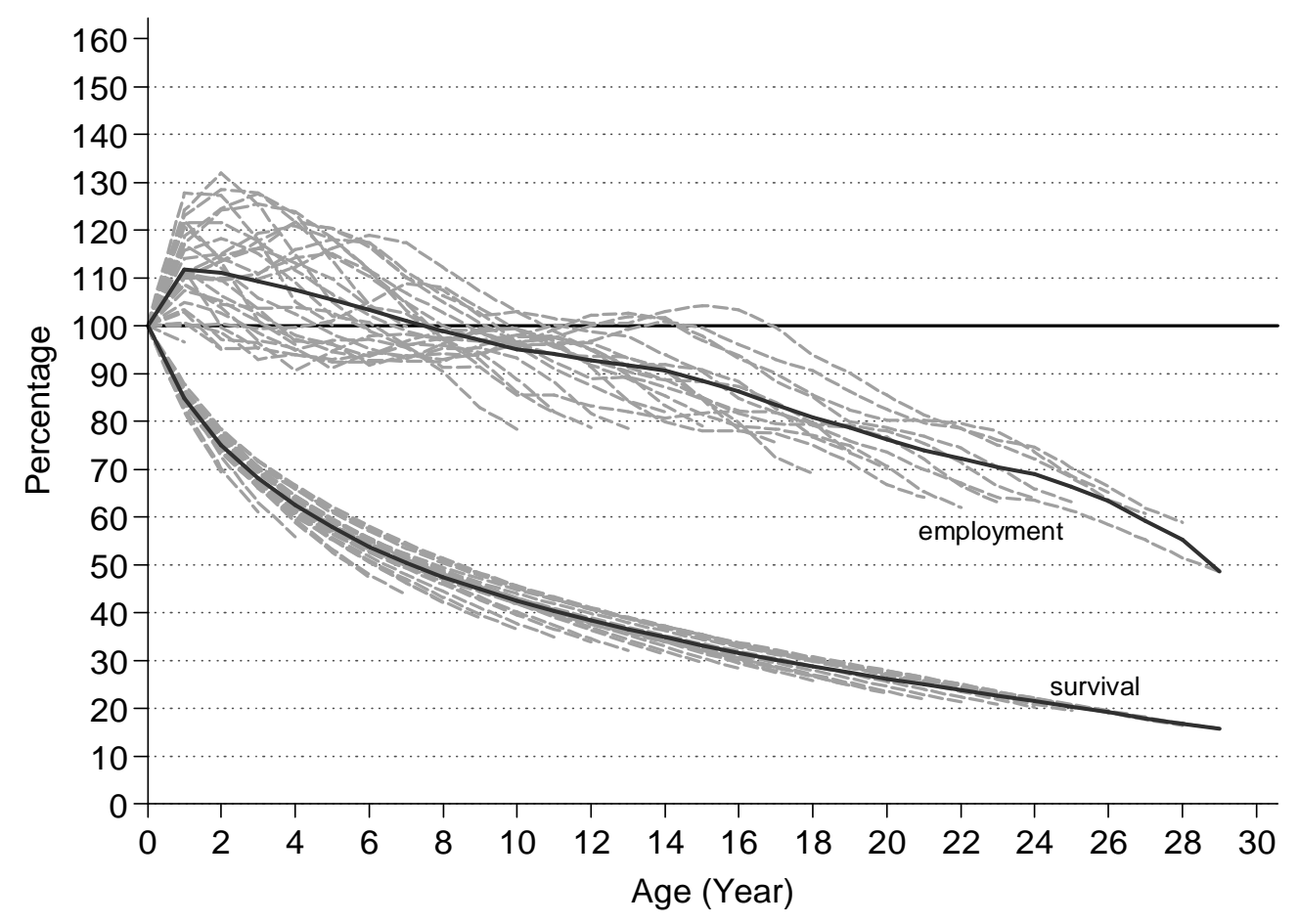

\footnotetext{
${ }^{2}$ See, for example, Storey $(1994,113-119)$ for a review of the cohort studies that were available until the early1990s. According to a recent analysis for West Germany (Schindele and Weyh, 2011), about 40 percent of the start-ups exit the market in the first five years.
} 
The CER working Paper Series on Entrepreneurship and Innovation

Notes: Thin dotted lines represent individual cohorts; dark thick line represent average values over all cohorts for which information in the respective year is available.

Figure 2: Evolution of employment and survival rates in entry cohorts in West Germany 1976-2004 (Source: Schindele and Weyh, 2011)

Recent empirical studies for the case of Germany have demonstrated that the indirect effects of new business formation on incumbents tend to be considerably larger than the direct effects. According to the analysis of Fritsch and Noseleit (2013a) for West Germany, the start-ups of a certain vintage have on average led to a 3.8 percent increase in regional employment over a period of 11 years. About 40 percent of this increase is attributable to employment in new businesses (the direct effect); the other 60 percent is due to indirect effects. Hence, disregarding indirect effects on incumbents is not a forgivable oversight, but a mistake so big that it may render the analysis meaningless!

The recognition that the effects of new business formation emerge from competition between newcomers and incumbent firms ${ }^{3}$ means that the magnitude of the effects will depend on:

- The quality of the newcomers in terms of the competitive pressure they exert on incumbents. A strongly challenging entry such as a radical innovation introduced by a Schumpeterian entrepreneur may revolutionize the market and create a completely new industry; the effect of imitative new businesses will be much smaller or even negligible. $\Rightarrow$ The number of start-ups or the overall start-up rate is not so important. Measures that account for the quality of start-ups are desirable.

- The way the incumbent firms react to the challenge of new competition, for example, by product innovation, process innovation, outsourcing to low-wage regions, and the like.

- The characteristics of the competitive process, which may be considerably dependent of factors such as the number of competitors, demand conditions, and technological developments, as well as by barriers to entry and exit.

\section{Differences of the effect of new business formation across regions}

The complex competitive process between newcomers and incumbents that may stimulate regional development is considerably shaped by industry-specific conditions and by the regional environment (see Figure 3). Accordingly, empirical analyses have shown remarkable variation in the contribution of new businesses to employment across regions. In some regions, the effect has been found to be even negative (see, for example, Acs and Mueller, 2008; van Stel and Suddle, 2008; Mueller, van Stel and Storey, 2008). Generally, the effects of new business formation on employment change tend to be much more

\footnotetext{
${ }^{3}$ One indication for the importance of the competition between the newcomers and incumbent firms is that the longrung effect of new business formation on the development of the incumbents as a whole is found to be significantly positive (Fritsch and Noseleit, 2013b).
} 
The CER working Paper Series on Entrepreneurship and Innovation

pronounced in high-density areas as compared to rural regions. The reasons behind this phenomenon are, however, not yet well understood.

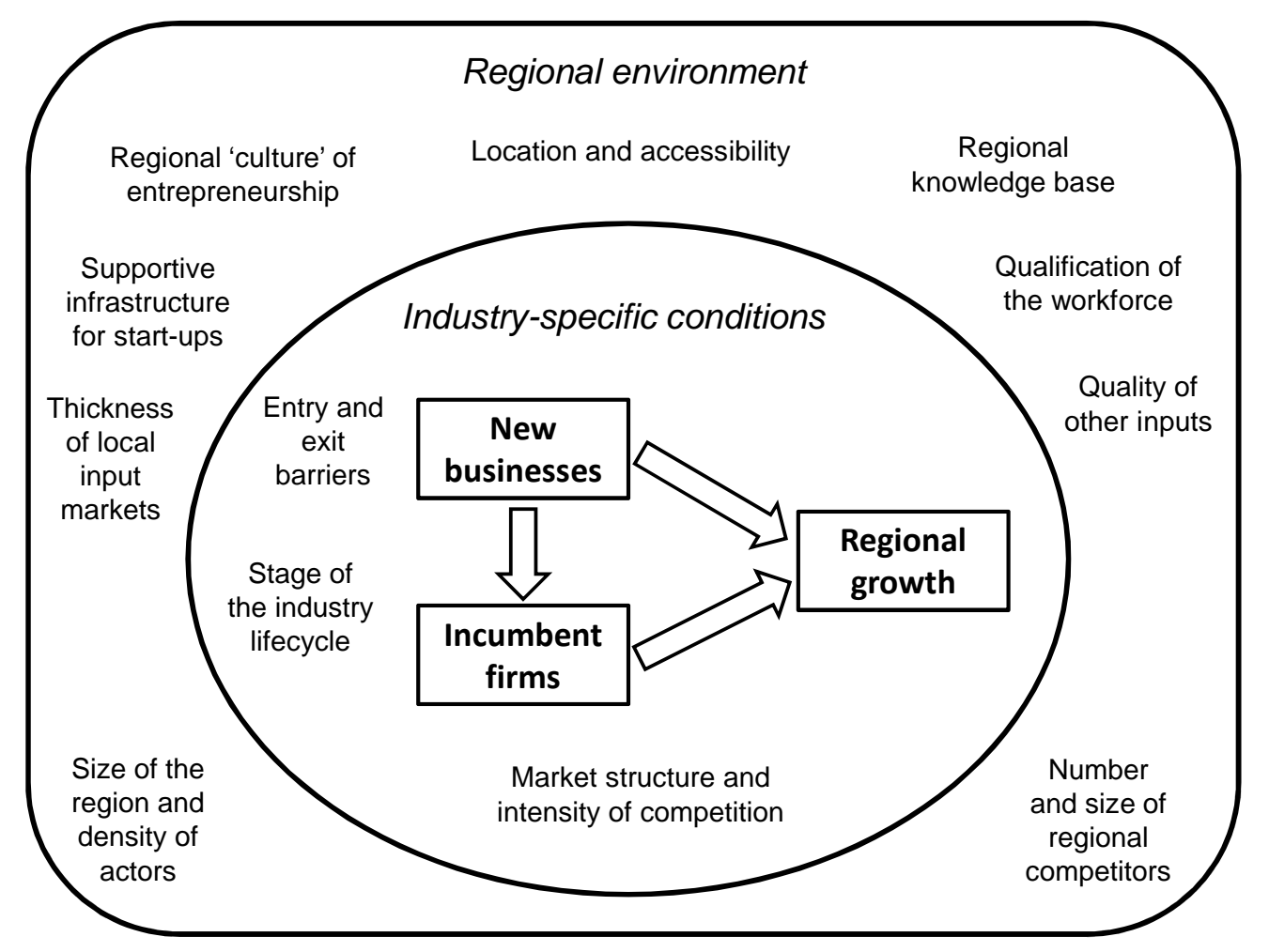

Figure 3: Factors that may determine the effect of new business formation on regional development

Factors that can be regarded conducive for positive growth effects of new business formation include (among others):

- the size and quality of the regional knowledge base as a source of new ideas and entrepreneurial opportunities (new business formation is a part of the regional innovation system);

- the qualification of the regional workforce;

- the availability and the quality of other inputs (thick input markets);

- the regional "culture" of entrepreneurship (Glaeser, Kerr and Kerr, 2012; Fritsch and Wyrwich, 2014; Obschonka, et al., 2013).

- the available supportive infrastructure for start-ups (consulting, finance for start-ups);

- the intensity of local competition between newcomers and incumbent firms on the inputand the output market (Fritsch and Noseleit, 2013b). 


\section{The persistence of regional entrepreneurship and the scope for policy}

Last but not least: Recent studies have found an important role of history for regional entrepreneurship and its effects. At least in some high income countries the regional levels of new business formation tend to be rather persistent over time (Andersson and Koster, 2011; Fotopoulos, 2013; Fritsch and Wyrwich, 2014) so that the new firm formation league table exhibits little or no variation over long periods of time. As a consequence, the positive effects of having a well-developed 'culture' of entrepreneurship in a region may be rather long-lasting. This raises two important questions:

- What explains this long-term persistence of regional levels of new business formation and the intergenerational transfer of entrepreneurial attitudes?

- How can those regions with low rates of new firm formation wishing to become more entrepreneurial as a route to economic improvement "move up the new firm formation league table"?

\section{Questions for discussion}

General question:

1. What are the most promising starting points for a policy that wants to stimulate challenging new businesses?

More specific questions:

2. How can the regional knowledge base for entrepreneurship be improved?

3. What kind of entrepreneurship policy can be regarded appropriate as a stimulation of regional growth?

4. Is there a role for financial subsidies for start-ups given the importance of an undistorted competitive process according to a survival of the fittest scenario?

5. In how far is the standard tool-box of regional policy instruments appropriate for an entrepreneurship policy that aims at stimulating growth?

6. What are the most relevant questions for further research on the issue? 


\section{References}

Acs, Zoltan J. and Pamela Mueller (2008): Employment Effects of Business Dynamics: Mice, Gazelles and Elephants. Small Business Economics, 30, 85-100.

Acs, Zoltan J. (2011): High-Impact Firms: Gazelles Revisited. In Michael Fritsch (ed.), Handbook of Research on Entrepreneurship and Regional Development, Cheltenham: Elgar, 133-174.

Andersson, Martin and Sierdjan Koster (2011): Sources of persistence in regional start-up rates - Evidence from Sweden. Journal of Economic Geography, 11, 179-201.

Baumol, William J. (2004): Entrepreneurial Enterprises, Large Established Firms and Other Components of the Free-Market Growth-Machine. Small Business Economics, 23, 9-21.

Boschma, Ron (2004): Competitiveness of Regions from an Evolutionary Perspective. Regional Studies, 38, 1001-1014.

Boschma, Ron and Koen Frenken (2011): The emerging empirics of evolutionary economic geography. Journal of Economic Geography, 11, 295-307,

Fotopoulos, Georgios (2013): On the spatial stickiness of UK New firm formation rates. Journal of Economic Geography. DOI 10.1093/jeg/lbt011.

Fritsch, Michael (2013): New Business Formation and Regional Development-A Survey and Assessment of the Evidence. Foundations and Trends in Entrepreneurship, 9, 249-364.

Fritsch, Michael and Florian Noseleit (2013a): Investigating the Anatomy of the Employment Effects of New Business Formation. Cambridge Journal of Economics, 37, 349-377.

Fritsch, Michael and Florian Noseleit (2013b): Indirect Employment Effects of New Business Formation Across Regions: The Role of Local Market Conditions. Papers in Regional Science, 92, 361-382.

Fritsch, Michael and Michael Wyrwich (2014): The Long Persistence of Regional Entrepreneurship Culture: Germany 1925-2005. Regional Studies, 48 (forthcoming).

Glaeser, Edward L., Sari Pekkala Kerr and William R. Kerr (2012): Entrepreneurship and Urban Growth: An Empirical Assessment with Historical Mines. Harvard Business School Working Paper Number 13-015. Cambridge, MA.

Henrekson, Magnus and Dan Johansson (2010): Gazelles as job creators: a survey and interpretation of the evidence. Small Business Economics, 35, 227-244.

Klepper, Steven (1997): Industry Life Cycles. Industrial and Corporate Change, 6, 145181.

Marshall, Alfred (1920): Principles of Economics. 8th edition, London: MacMillan.

Mueller, Pamela, André van Stel and David J. Storey (2008): The Effect of New Firm Formation on Regional Development over Time: The Case of Great Britain. Small Business Economics, 30, 59-71.

Obschonka, Martin, Eva Schmitt-Rodermund, Samuel D. Gosling and Rainer K. Silbereisen (2013): The Regional Distribution and Correlates of an Entrepreneurship-Prone Personality Profile in the United States, Germany, and the United Kingdom: A Socioecological Perspective. Journal of Personality and Social Psychology, DOI 10.1037/a0032275. 
Saviotti, Pier Paolo and Andreas Pyka (2004): Economic development, variety and employment. Revue Économique, 55, 1023-1049.

Schindele, Yvonne and Antje Weyh (2011): The Direct Employment Effects of New Businesses in Germany Revisited-An Empirical Investigation for 1976-2004. Small Business Economics, 36, 353-363.

Storey, David J. (1994): Understanding the Small Business Sector. London: Routledge.

Schumpeter, Joseph A. (1911/1934): Theorie der wirtschaftlichen Entwicklung, Leipzig 1911: Duncker \& Humblot; revised English edition: The Theory of Economic Development. Cambridge, MA: Cambridge University Press.

Schumpeter, Joseph A. (1942): Capitalism, Socialism and Democracy. New York: Harper \& Row. 